Article

\title{
In Vitro Antioxidant Activity of Purple Grape Juice (Vitis Labrusca) against Temozolamide Treatment in Rat Brains
}

\author{
Tatiane Gabardo ${ }^{1}$, Marina Rocha Frusciante ${ }^{1}$, Jessica Pereira Marinho ${ }^{1}$, Manuela dos Santos ${ }^{1}$, \\ Ana Lúcia Abujamra ${ }^{1,2}$, Caroline Dani ${ }^{1}$ and Cláudia Funchal ${ }^{1, * \mathbb{D}}$ \\ 1 Centro Universitário Metodista-IPA, Rua Coronel Joaquim Pedro Salgado, 80, \\ Porto Alegre 90420-060, RS, Brazil; tatiane.gabardo@gmail.com (T.G.); \\ marina_frusciante@hotmail.com (M.R.F.); marinhow31@gmail.com (J.P.M.); \\ manuelasanttos@gmail.com (M.d.S.); abujamra.ana@gmail.com (A.L.A.); carolinedani@yahoo.com.br (C.D.) \\ 2 Univates, Programa de Pós-Graduação em Biotecnologia, Rua Avelino Tallini, 171, \\ Lajeado 95900-000, RS, Brazil \\ * Correspondence: csfunchal@yahoo.com.br; Tel.: +55-51-3316-1233
}

Received: 15 November 2018; Accepted: 30 November 2018; Published: 4 December 2018

\begin{abstract}
Considering that grape juice has high levels of phenolic compounds that produce beneficial physiological effects, important for the maintenance of redox balance, the aim of this study was to evaluate the in vitro neuroprotective effect of purple grape juice on the oxidative damage caused by temozolomide (TMZ) in the cerebral cortex, hippocampus, and cerebellum of Wistar rats. In pre-incubation, TMZ increased thiobarbituric acid reactive substances (TBARS) in the cerebral cortex and cerebellum, enhanced protein oxidation in all tissues studied, increased superoxide dismutase (SOD) activity in the hippocampus, decreased SOD activity in the cerebellum, and enhanced catalase (CAT) activity in the cerebral cortex and cerebellum. In co-incubation, there was enhanced protein oxidation in the cerebral cortex and cerebellum, decreased SOD activity in the cerebellum, inhibition of CAT activity in the hippocampus, and increased CAT activity in the cerebellum. Purple grape juice improved these oxidative alterations. Therefore, the intake of grape juice might have a protective effect against diseases that affect the oxidative status of the central nervous system.
\end{abstract}

Keywords: grapes; temozolomide; brain; oxidative stress; antioxidant

\section{Introduction}

Temozolomide (TMZ) is an alquilating agent used as a chemotherapeutic drug in patients diagnosed with glioma. Being a lipophilic molecule, it can easily cross the blood-brain barrier after administration [1,2]. TMZ is prescribed for the treatment of malignant gliomas since it is able to increase the quality of life and survival of patients [3,4]. On the other hand, TMZ has a cytotoxic effect on both tumor cells and healthy cells, causing an increase in the formation of free radicals and reactive species [1,5-7].

The central nervous system is extremely sensitive to damage caused by oxidative stress because of its high composition of unsaturated fatty acids, large accumulation of iron, high demand for oxygen metabolism, and low capacity for cellular regeneration [8,9]. Therefore, dietetic phenolic compounds have an important physiological role in maintaining the redox balance [10]. In this context, it is well established that the products derived from grapes (e.g., grape juice, grapevine leaf extracts, grape seed extracts, resveratrol) are rich in bioactive compounds that act as antioxidants capable of inhibiting the damage caused by oxidative stress in the central nervous system [11-16]. 
Grape juice has great prominence among the foods that are rich in polyphenols, demonstrating an important antioxidant activity [11,14,17-19]. Moreover, world consumption of grape juice has grown every year; Brazil and the United States of America are the largest producers and consumers of this beverage [20].

Considering that some studies demonstrated that grape juice has neuroprotective, cardioprotective, hepatoprotective, anticarcinogenic, anti-atherogenic, anti-inflammatory, antioxidant, and antimicrobial effects $[11,14,17,19,21,22]$, the purpose of this study was to evaluate the in vitro antioxidant and protective effect of purple grape juice (Vitis labrusca) on the oxidative damage caused by TMZ in different Wistar rats brain tissue.

\section{Materials and Methods}

\subsection{Compounds and Reagents}

TMZ, adrenaline, and 2,4-dinitrophenylhydrazine (DNPH) were obtained from Sigma (St. Louis, MO, USA). TMZ was dissolved in dimethyl sulfoxide (DMSO) to prepare a stock solution. The final solution of TMZ was prepared before each use, at a final concentration of $0.1 \%$ DMSO, which did not change any of the parameters tested. Thiobarbituric acid was purchased from Merck (Darmstadt, Germany). All other reagents were of analytical grade and were obtained from local suppliers.

\subsection{Grape Juice Chemical Evaluation and Phenolic Compound Content}

The purple grape juice used in this study was obtained from Vitis labrusca grapes, Bordo cultivar, obtained from Vinícola Quinta do Morgado (Flores da Cunha, Rio Grande do Sul, RS, Brazil). Expiration dates were observed, and the same brands were used for the entire study. Grape juices were manufactured in 2015 by extraction, with a subsequent pressing in order to separate the pulp, then pasteurized at $85{ }^{\circ} \mathrm{C}$, immediately followed by bottling at $80^{\circ} \mathrm{C}$.

The chemical composition was determined using the methods described by Zoecklein et al. [23]. Total acidity, volatile acidity, total carbohydrates, density, and $\mathrm{pH}$ were determined according to the Association Official Agriculture Chemistry (AOAC) International official methodologies [24]. Total phenol content was measured using Singleton and Rossi's modification of Folin-Ciocalteau's colorimetric method [25]. High performance liquid chromatography (HPLC) analysis was used to quantify the presence of individual phenolic compounds. Before HPLC analysis, $5 \mathrm{~mL}$ of each sample was filtered through a cellulose membrane with a $0.20-\mathrm{mm}$-diameter pore size. The equipment used in the analysis consisted of an LC-DAD Series 1100 (Agilent Technologies, Palo Alto, CA, USA) liquid chromatographic system with a diode array detector system.

\subsection{Animals}

Adult male Wistar rats (90-days-old; 300 g) were obtained from our own breeding colony ( $\mathrm{N}=8-10$ animals/group). They were maintained at $22 \pm 2{ }^{\circ} \mathrm{C}$, on a 12-h light/12-h dark cycle, with free access to food and water. The "Principles of laboratory animal care" (National Institutes of Health (NIH) publication no 80-23, revised in 1996) were followed in all experiments, and our research protocol was approved by the Ethics Committee for Animal Experimentation of the Centro Universitário Metodista-IPA, Porto Alegre, Brazil. All efforts were made to minimize animal suffering and to use only the number of animals necessary to produce reliable scientific data.

\subsection{Tissue Preparation}

The animals were euthanized by decapitation. The cerebral cortex, hippocampus, and cerebellum were dissected and kept chilled until homogenization, which was performed in $1.5 \%$ potassium chloride $(\mathrm{KCl})$ with a ground glass type Potter-Elvejhem homogenizer (Kimble Chase Life Science, Rockwood, TN, USA). The homogenates were centrifuged at $800 \times \mathrm{g}$ for $10 \mathrm{~min}$ at $4{ }^{\circ} \mathrm{C}$; the pellet was then discarded, and the supernatants were kept at $-70^{\circ} \mathrm{C}$ until the experiments were performed. 


\subsection{Incubation}

The tissues were divided into four experimental groups: Group 1: tissue homogenate + sodium chloride $(\mathrm{NaCl})(0.89 \%)$; Group 2: tissue homogenate + TMZ (1 mM); Group 3: tissue homogenate + grape juice $(40 \% w / v)$; Group 4: tissue homogenate + TMZ $(1 \mathrm{mM})+$ grape juice $(40 \% w / v)$. Two different experimental approaches were utilized.

Pre-treatment (pre-incubation with grape juice): homogenates of cerebral cortex, hippocampus and cerebellum were pre-incubated at $37^{\circ} \mathrm{C}$ for $1 \mathrm{~h}$ with grape juice and, afterwards, incubated at $37^{\circ} \mathrm{C}$ for $30 \mathrm{~min}$ in the presence of TMZ and grape juice. The controls were pre-incubated and incubated in the presence of $\mathrm{NaCl}$ only.

Co-treatment (co-incubation with grape juice): homogenates of cerebral cortex, hippocampus and cerebellum were incubated at $37^{\circ} \mathrm{C}$ for $1 \mathrm{~h}$ and $30 \mathrm{~min}$ in the presence of TMZ and grape juice. Controls were incubated in the presence of $\mathrm{NaCl}$ only.

\subsection{Parameters of Oxidative Stress}

For the thiobarbituric acid reactive substances (TBARS) assay, trichloroacetic acid (TCA) $(10 \% w / v)$ was added to the homogenate to precipitate proteins and to acidify samples [26]. This mixture was then centrifuged $(3000 \times g, 10 \mathrm{~min})$. The protein-free sample was extracted and thiobarbituric acid (TBA) $(5 \% w / v)$ was added to the reaction medium. Tubes were placed in a water bath $\left(100{ }^{\circ} \mathrm{C}\right)$ for $15 \mathrm{~min}$. Absorbance was read at $530 \mathrm{~nm}$ in a spectrophotometer (T80 UV/VIS Spectrometer, PG Instruments, Alma Parck, Lutterworth, UK). Commercially available malondialdehyde was used as a standard. Results were expressed as $\mathrm{nmol} / \mathrm{mg}$ protein. The carbonyl assay was used to determine oxidative damage to proteins. Homogenates were incubated with 2,4-dinitrophenylhydrazine (DNPH, $10 \mathrm{mM}$ ) in $2 \mathrm{M} \mathrm{HCl}$ for $1 \mathrm{~h}$ at room temperature, in the dark. Samples were mixed every $15 \mathrm{~min}$. Next, $20 \%(w / v)$ TCA was added to the tubes, which were then left on ice for $10 \mathrm{~min}$ and centrifuged for $5 \mathrm{~min}$ at $1000 \times g$, to collect the protein precipitates. Another wash was performed with $10 \%$ TCA. The pellet was then washed three times with ethanol:ethyl acetate (1:1) $(v / v)$. The final precipitates were dissolved in $6 \mathrm{M}$ guanidine hydrochloride, and the solutions were allowed to stand for $10 \mathrm{~min}$ at $37^{\circ} \mathrm{C}$, at which point they were read at $370 \mathrm{~nm}$ in a spectrophotometer [27]. The results were expressed as $\mathrm{nmol} / \mathrm{mg}$ protein.

The sulfhydryl assay was based on the reduction of 5,5'-dithio-bis(2-nitrobenzoic acid) (DTNB) by thiols, generating a yellow derivative 5-thio-2-nitrobenzoic acid (TNB), whose absorption was determined spectrophotometrically at $405 \mathrm{~nm}$ in a spectrophotometer [28]. Briefly, $5 \mathrm{mM}$ DTNB was added to $16 \mu \mathrm{L}$ of sample. This was followed by a $30 \mathrm{~min}$ incubation at room temperature in a dark room, and absorbance was measured at $405 \mathrm{~nm}$. The sulfhydryl content is inversely correlated to oxidative damage to proteins. Results were reported as $\mathrm{nmol} / \mathrm{mg}$ protein.

Superoxide dismutase (SOD) activity, expressed as USOD/mg protein, was based on the decrease in the rate of autocatalytic adrenochrome formation at $480 \mathrm{~nm}$ [29]. Catalase (CAT) activity was determined by following the decrease in hydrogen peroxide $\left(\mathrm{H}_{2} \mathrm{O}_{2}\right)$ measured at $240 \mathrm{~nm}$ and expressed as CAT/mg protein [30].

\subsection{Protein Determination}

Protein concentrations were determined by the method of Lowry et al. [31] using bovine serum albumin as standard.

\subsection{Statistical Analysis}

Data were analyzed by a one-way analysis of variance (ANOVA) followed by Tukey post-hoc test to determine differences between groups. Values of $p<0.05$ were considered to be significant. All analyses were carried out using the SIGMASTAT ${ }^{\circledR}$ software (version 3.10, Systat Software, San Jose, CA, 
USA) and Statistical Package for Social Sciences (SPSS) software (version 19.0, International Business Machines Corporation, New York, NY, USA).

\section{Results}

\subsection{Grape Juice Composition}

Table 1 shows the chemical composition of purple grape juice by the determination of total acidity, total volatile acidity, total carbohydrates, density, and $\mathrm{pH}$. Table 2 shows the total and isolated phenolic content in purple grape juice, with the identification of catechin, epicatechin, resveratrol, and naringin in the sample analyzed.

Table 1. Chemical composition of purple grape juice (Vitis labrusca).

\begin{tabular}{cc}
\hline Parameter & Purple Grape Juice \\
\hline Total acidity $(\mathrm{mEq} / \mathrm{L})$ & $109.00 \pm 0.01$ \\
Total volatile acidity (mEq/L) & $3.00 \pm 0.01$ \\
Total carbohydrates (g/L) & $141.24 \pm 0.01$ \\
Density $\left(20^{\circ} \mathrm{C}\right)$ & $1.062 \pm 0.01$ \\
$\mathrm{pH}$ & $3.53 \pm 0.08$ \\
\hline
\end{tabular}

Data are presented as mean \pm standard deviation.

Table 2. Total and isolated phenolic content in purple grape juice (Vitis labrusca).

\begin{tabular}{cc}
\hline Phenolic Compound (mg/L) & Purple Grape Juice \\
\hline Total phenolic compound & $17.88 \pm 0.28$ \\
Catechin & $1.17 \pm 0.01$ \\
Epicatechin & $5.02 \pm 0.06$ \\
Resveratrol & $0.24 \pm 0.01$ \\
Naringin & $38.23 \pm 0.48$ \\
\hline
\end{tabular}

Data are presented as mean \pm standard deviation.

3.2. Effect of TMZ in Pre-Treatment and Co-Treatment with Purple Grape Juice on Oxidative Stress Parameters in Different Brain Structures of Rats

It was observed that TMZ increased TBARS levels in the cerebral cortex and cerebellum; TBARS levels in the hippocampus of rats remained unchanged (Figure 1A). Purple grape juice was able to prevent lipid damage caused by TMZ in the cerebral cortex and cerebellum (Figure 1A). With co-incubation, TMZ did not change the levels of TBARS in the cerebral cortex, hippocampus and cerebellum of rats (Figure 1B). Purple grape juice alone or associated with TMZ enhanced TBARS levels in the cerebral cortex only (Figure 1B).

In pre-incubation, TMZ also enhanced protein oxidation, as measured by carbonyl group formation in the cerebral cortex, hippocampus, and cerebellum of the rats (Figure 1C). Furthermore, purple grape juice prevented the protein damage caused by TMZ in all the tissues tested (Figure 1C). It was also verified that, in the co-incubation treatment, TMZ enhanced protein oxidation in the cerebral cortex and cerebellum of the rats (Figure 1D), and that purple grape juice prevented the protein damage caused by TMZ in both tissues. Additionally, grape juice alone or associated with TMZ reduced carbonyl levels in the rat hippocampus (Figure 1D). 

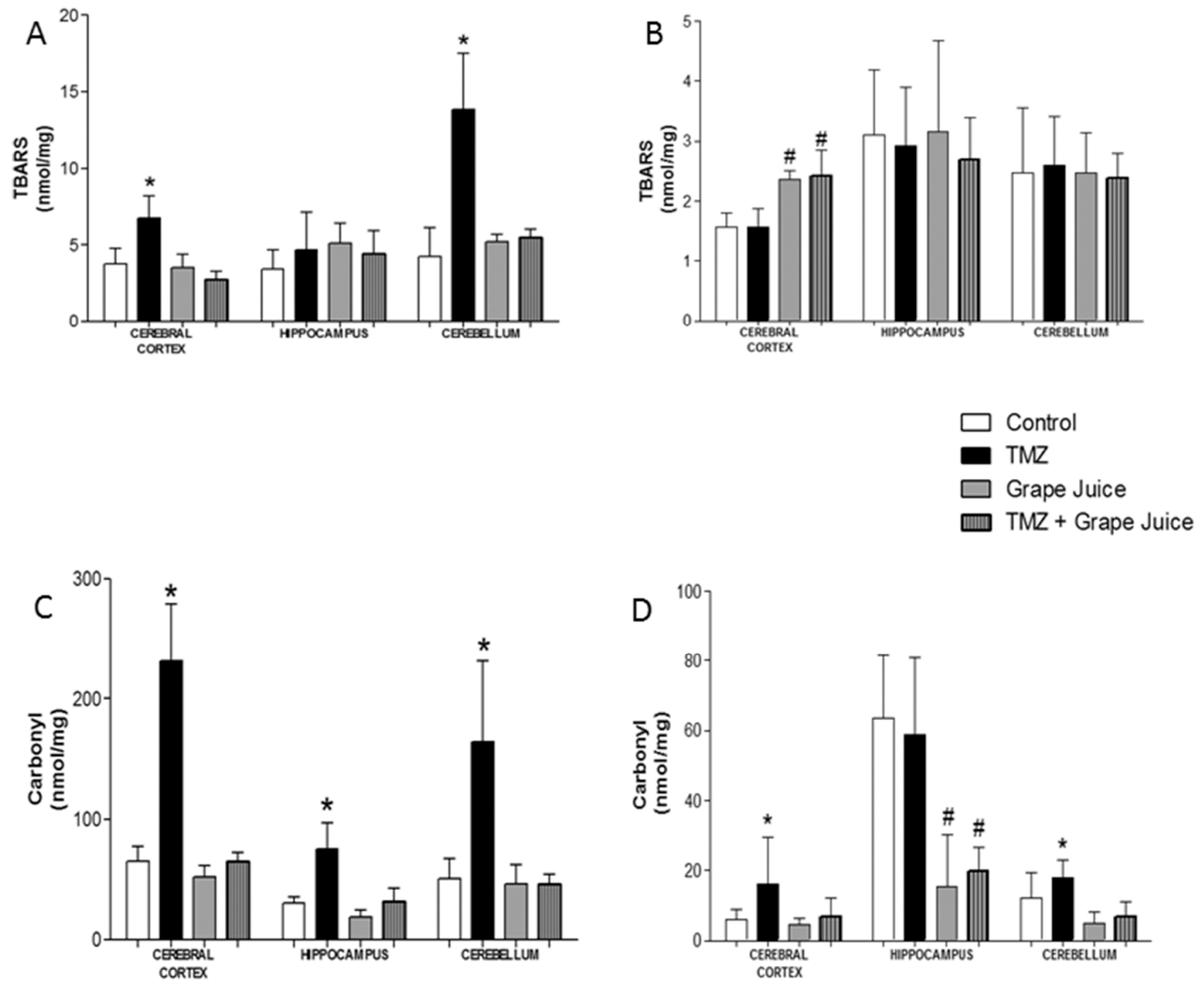

Figure 1. Effect of temozolomide (TMZ) and pre-incubation with purple grape juice on thiobarbituric acid reactive substances (TBARS) (A) and carbonyl (C) and effect of co-incubation with TMZ and purple grape juice on thiobarbituric acid reactive substances (TBARS) (B) and carbonyl (D) in the cerebral cortex, hippocampus, and cerebellum of rats. Data are expressed as mean \pm standard deviation. $p<0.05$ from other groups; \# $p<0.05$ from control and TMZ. $\mathrm{N}=8-10$ animals/group.

In order to determine non-enzymatic antioxidant defenses, the sulfhydryl content was measured. It was verified that TMZ did not affect sulfhydryl levels in the rat cerebral cortex, hippocampus, or cerebellum, regardless of treatment as pre-incubation or as co-incubation (Figure 2A,B).

To verify enzymatic antioxidant defenses, the SOD and CAT activity were evaluated. In pre-incubation, TMZ increased SOD activity in the hippocampus while decreasing its activity in the cerebellum (Figure 2C). Purple grape juice was able to prevent the increase in SOD activity caused by TMZ in rat hippocampus (Figure 2C). Interestingly, purple grape juice in the presence or absence of TMZ decreased SOD activity in the cerebral cortex and cerebellum of rats (Figure 2C). On the other hand, in co-incubation, TMZ decreased SOD activity in the cerebellum without changing its activity in the cerebral cortex and hippocampus (Figure 2D). Purple grape juice in the presence or absence of TMZ decreased the activity of SOD in all tissues tested (Figure 2D).

In pre-incubation, TMZ also increased CAT activity in the cerebral cortex and cerebellum of the rats (Figure 2E). Purple grape juice prevented the increase in CAT activity caused by TMZ in the cerebral cortex and cerebellum (Figure 2E). In co-incubation, TMZ inhibited CAT activity in the hippocampus and enhanced its activity in the cerebellum of rats (Figure 2F). Purple grape juice prevented these alterations in CAT activity. Interestingly, purple grape juice in the presence or absence of TMZ increased the activity of CAT in the cerebral cortex (Figure 2F). 

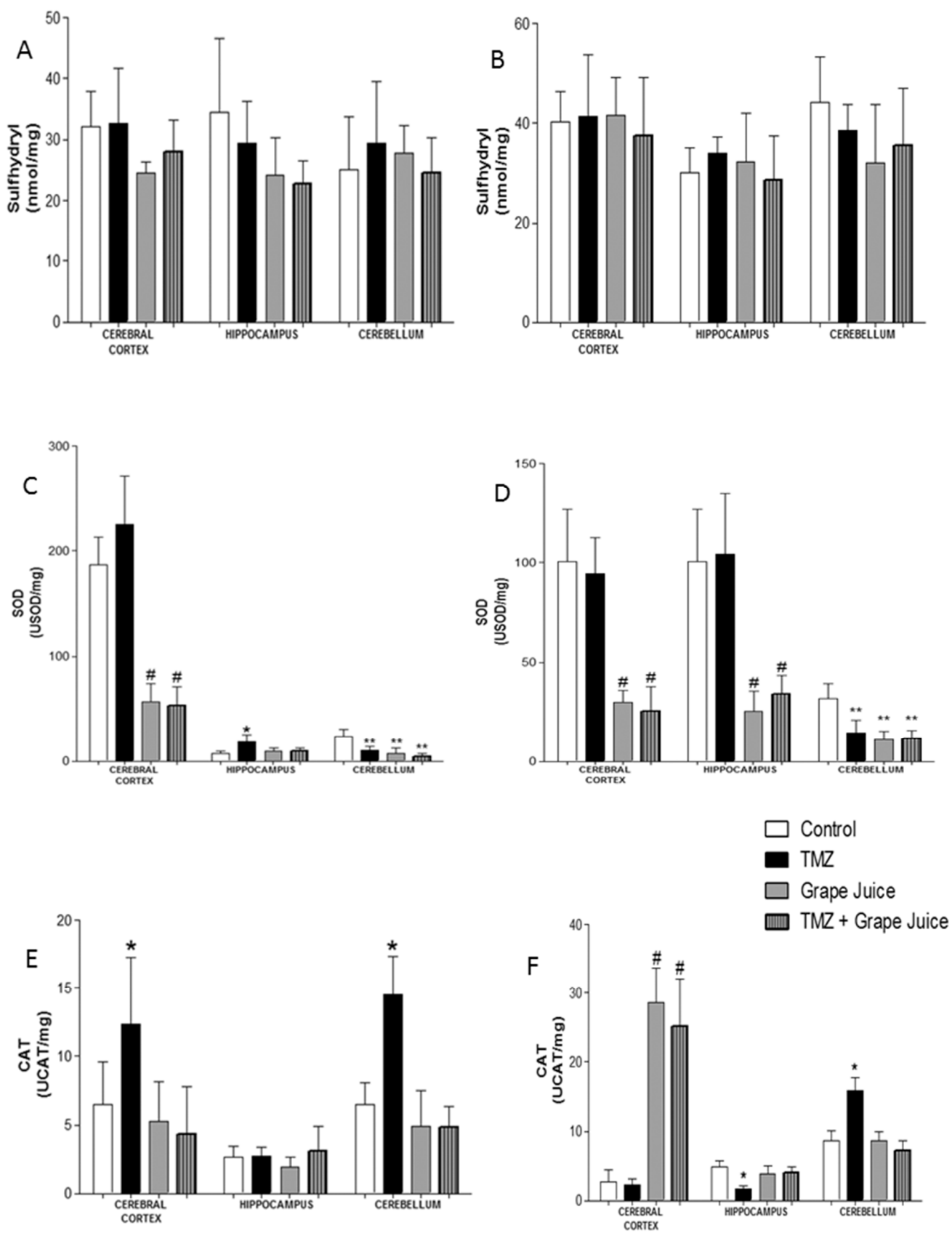

Figure 2. Effect of TMZ and pre-incubation with purple grape juice on sulfhydryl groups (A), superoxide dismutase (SOD) activity (C) and catalase (CAT) activity (E) and effect of co-incubation with TMZ and purple grape juice on sulfhydryl groups (B), superoxide dismutase (SOD) activity (D) and catalase (CAT) activity (F) in the cerebral cortex, hippocampus and cerebellum of rats. Data are expressed as mean \pm standard deviation. ${ }^{*} p<0.05$ from other groups; ${ }^{* *} p<0.05$ from control; $\# p<0.05$ from control and TMZ. $N=8-10$ animals/group.

\section{Discussion}

TMZ was utilized in vitro as an experimental model for oxidative damage. Its mechanism of action is based on the release of 5-(3-methyl-1-triazen-1-yl) imidazole-4-carboxamide compound (MTIC), generated by non-enzymatic hydrolysis of TMZ at physiological $\mathrm{pH}$, without requiring hepatic metabolism of this drug. MTIC-activated DNA is methylated at the N7 and O6 position in guanines, and at the N3 position in adenines, resulting in N7-methylguanine (70\%), O6-methylguanine $(5 \%)$, and N3-methyladenine (9\%). O6-methylguanine is the main product responsible for TMZ's 
cytotoxicity, inducing DNA damage followed by cell cycle arrest and death. All of these factors are caused by incorrect pairing with thymine and could promote an increase in free radicals and reactive species leading to oxidative stress [5-7].

With this in mind, Lin et al. [32], using the human grade IV glioblastoma cell lines U87MG and GBM8401, showed that TMZ has the ability to produce reactive oxygen species leading to cell death by apoptosis and autophagy, and that the combination of resveratrol with TMZ increased the efficacy of TMZ by suppressing TMZ-induced autophagy. Another study using a selected human glioblastoma cell line (SHG44) combining TMZ with resveratrol showed that this association was able to significantly increase the production of reactive oxygen species, and therefore, that resveratrol can increase the antitumor effect mediated by TMZ [33]. On the other hand, another study [34] using human glioblastoma cells in culture (U87MG) showed that TMZ is significantly associated with curcumin increases production of reactive oxygen species, which increased TMZ's antitumor activity.

In the present study, it was demonstrated that TMZ promoted an increase in the lipid peroxidation (TBARS) levels in the rats' cerebral cortex and cerebellum, without changing these levels in the hippocampus; pre-incubation with purple grape juice was able to prevent lipid damage induced by TMZ in the rats' cerebral cortex and cerebellum. Moreover, co-incubation with TMZ and purple grape juice did not change TBARS levels in any of the three brain structures studied, however, purple grape juice, associated or not with TMZ, promoted an increase in lipid peroxidation levels in the rats' cerebral cortex. These results corroborate with the in vivo study of Pinheiro et al. [35], where animals were pre-treated with Vitis vinifera (cv. Cabernet Sauvignon) grape seed extract via intraperitoneal injection and, afterwards, received methotrexate, an anti-folate used for the treatment of cancer and some inflammatory diseases, via intraperitoneal injection. The authors observed a TBARS increase in the animals' hippocampus, kidney, and liver, and that treatment with grape seed extract protected against lipid damage in these tissues.

The present results are also consistent with other studies that showed that purple grape juice was able to prevent lipid damage caused by carbon tetrachloride $\left(\mathrm{CCl}_{4}\right)$ in the substantia nigra of rats [18]. Cardozo et al. [14] showed that animals treated with a high-fat diet had an increase in lipid peroxidation in the cerebral cortex and hippocampus, and that organic purple grape juice was able to prevent this increase in the cerebral cortex. Furthermore, an in vitro study using sodium azide as an inducer of lipid peroxidation showed that white grape juice (organic and conventional) protected the cerebral cortex against TBARS [15]. Moreover, the enhanced TBARS levels in the cerebral cortex caused by purple grape juice might be due to its consumption in high doses, in which the polyphenols could have a pro-oxidant effect [36,37].

Additionally, TMZ increased the formation of carbonyl groups in the cerebral cortex, hippocampus, and cerebellum of rats, indicating an increase in protein oxidation. Pre-incubation with purple grape juice was capable of protecting against damage to these tissues. Co-incubation with $\mathrm{TMZ}$ and purple grape juice resulted in the oxidation of proteins in the cerebral cortex and cerebellum of rats, and purple grape juice was able to protect against this damage. In addition, purple grape juice, alone or in combination with TMZ, was able to reduce carbonyl levels in the rat hippocampus. Our results corroborate with those of Ongaratti et al. [15], where it was demonstrated, in an in vitro study, that white grape juice (organic and conventional) was able to prevent damage to proteins caused by sodium azide in the rat cerebral cortex. Moreover, Cardozo et al. [14] showed that animals receiving conventional grape juice had their brain tissues protected against protein damage due to high-fat diets. Rodrigues et al. [38] reported that organic and conventional grape juices prevented an increase in carbonyl groups induced by pentylenetetrazole (PTZ) in the brain. Furthermore, Vitis labrusca leaf extracts (organic and conventional) reduced protein damage caused by $\mathrm{CCl}_{4}$ in rat brain tissues [16].

One of the methods used for evaluating non-enzymatic defenses is the sulfhydryl technique. In our study, we found that both approaches (pre-incubation with purple grape juice and co-incubation with TMZ and purple grape juice), did not change the sulfhydryl content levels in the cerebral cortex, hippocampus, and cerebellum of the animals tested, demonstrating that there was no change in 
non-enzymatic antioxidant defenses. However, some studies have shown that grape juice is capable of increasing non-enzymatic defenses in the brain tissue of rats in a damage induction model $[14,15,38]$.

The antioxidant enzymes SOD and CAT are mainly responsible for enzymatic antioxidant defenses and represent the first barrier against oxidative damage. TMZ increased SOD activity in the hippocampus and decreased its activity in the rat cerebellum. Pre-incubation with purple grape juice was able to prevent enhanced SOD activity in the hippocampus, whereas pre-incubation with purple grape juice, alone or in combination with TMZ, inhibited the activity of this enzyme in the cerebral cortex and cerebellum. Moreover, co-incubation with TMZ and purple grape juice decreased SOD activity in the cerebellum without affecting its activity in the rats' cerebral cortex and hippocampus. In the co-incubation experiments, purple grape juice, alone or in combination with $\mathrm{TMZ}$, reduced SOD activity in all tissues studied. These results are in line with those presented by Ongaratti et al. [15], who observed that organic and conventional white grape juices decreased SOD activity and were unable to prevent the reduction caused by sodium azide. However, several studies showed that grape juice or its derivatives are capable of modulating enzymatic changes caused by certain damaging agents, such as high-fat diets [14], $\mathrm{CCl}_{4}$ [16], PTZ [38] or hydrogen peroxide [13].

In the co-incubation experiments, purple grape juice alone reduced the activity of SOD in the rats' cerebral cortex, hippocampus and cerebellum. Wohlenberg et al. [16] found that rats treated for 14 days with organic and conventional Vitis labrusca leaf extracts also had reduced SOD activity in the cerebral cortex and hippocampus. These results combined suggest that this reduction is due to the high concentration of polyphenols found in grape juice, demonstrating a pro-oxidant effect.

TMZ also increased CAT activity in the rats' cerebral cortex and cerebellum, and pre-incubation with purple grape juice prevented CAT activity increase in these tissues. Moreover, co-incubation with TMZ and purple grape juice inhibited CAT activity in the rats' hippocampus and increased CAT activity in their cerebellum; purple grape juice prevented these CAT changes. Furthermore, purple grape juice, regardless of whether in the presence or absence of TMZ, promoted an increase in CAT activity in the cerebral cortex. Our results are in line with Dani et al. [18], that found an increase in CAT activity in the rats' cerebral cortex, substantia nigra, and hippocampus after they received an intraperitoneal injection of $\mathrm{CCl}_{4}$. The animals treated previously with grape juice by gavage presented reduced CAT activity in the substantia nigra and hippocampus. Additionally, the reduced levels of carbonyl as well as the increase in CAT activity are a result of purple grape juice. Intake alone or in association with TMZ might be explained by the high amounts of polyphenols present in the grape juice and their antioxidant properties $[14,16,18]$.

\section{Conclusions}

In conclusion, the results of this study suggest that both pre-incubation and co-incubation with purple grape juice could have a protective effect against oxidative damage caused by TMZ. It is also important to emphasize that purple grape juice has antioxidant properties and, therefore, may be considered as a therapeutic adjuvant in the treatment of diseases that affect the brain oxidative homeostasis.

Author Contributions: Conceptualization, T.G. and C.F.; Formal analysis, T.G., C.D. and C.F.; Methodology, T.G., M.R.F., J.P.M., M.d.S. and A.L.A.; Project administration, C.F.; Resources, A.L.A., C.D. and C.F.; Supervision, C.F.; Writing-original draft, T.G., A.L.A., C.D. and C.F.; Writing-review \& editing, T.G., A.L.A. and C.F.

Funding: This work was supported by research grants from the Conselho Nacional de Desenvolvimento Científico e Tecnológico (CNPq), Fundação de Amparo à Pesquisa do Estado do Rio Grande do Sul (FAPERGS), and the Centro Universitário Metodista-IPA.

Acknowledgments: The author's would like to thank the Conselho Nacional de Desenvolvimento Científico e Tecnológico (CNPq), Fundação de Amparo à Pesquisa do Estado do Rio Grande do Sul (FAPERGS) and the Centro Universitário Metodista-IPA for the financial support.

Conflicts of Interest: The authors declare no conflicts of interest. 


\section{References}

1. Furnari, F.B.; Fenton, T.; Bachoo, R.M.; Mukasa, A.; Stommel, J.M.; Stegh, A.; Hahn, W.C.; Ligon, K.L.; Louis, D.N.; Brennan, C.; et al. Malignant astrocytic glioma: Genetics, biology, and paths to treatment. Genes Dev. 2007, 21, 2683-2710. [CrossRef] [PubMed]

2. Patel, M.; Mccully, C.; Godwin, K.; Balis, F.M. Plasma and cerebrospinal fluid pharmacokinetics of temozolomide in non-human primatas. J. Neurooncol. 2003, 61, 203-207. [CrossRef] [PubMed]

3. Mason, W.P.; Cairncross, J.G. Drug Insight: Temozolomide as a treatment for malignant glioma-impact of a recent trial. Nat. Clin. Pract. Neurol. 2005, 192, 88-95. [CrossRef] [PubMed]

4. $\quad$ Stupp, R.; Mason, W.P.; Van Den Bent, M.J.; Weller, M.; Fisher, B.; Taphoorn, M.J.; Belanger, K.; Brandes, A.A.; Marosi, C.; Bogdahn, U.; et al. Radiotherapy plus concomitant and adjuvant temozolomide for glioblastoma. N. Engl. J. Med. 2005, 352, 987-996. [CrossRef] [PubMed]

5. Mutter, N.; Stupp, R. Temozolomide: A milestone in neuro-oncology and beyond? Expert Rev. Anticancer Ther. 2006, 6, 1187-1204. [CrossRef] [PubMed]

6. Friedman, H.S.; Kerby, T.; Calvert, H. Temozolomide and treatment of malignant glioma. Clin. Cancer Res. 2000, 6, 2585-2597. [PubMed]

7. Marchesi, F.; Turriziani, M.; Tortorelli, G.; Avvisati, G.; Torino, F.; De Vecchis, L. Triazene compounds: Mechanism of action and related DNA repair systems. Pharmacol. Res. 2007, 56, 275-287. [CrossRef] [PubMed]

8. Weigand, M.A.; Laipple, A.; Plaschke, K.; Eckstein, H.H.; Martin, E.; Bardenheuer, H.J. Concentration changes of malondialdehyde across the cerebral vascular bed and shedding of L-selectin during carotid endarterectomy. Stroke 1999, 30, 306-311. [CrossRef]

9. Andersen, J.K. Oxidative stress in neurodegeneration: Cause or consequence? Nat. Med. 2004, 10, 182S-185S. [CrossRef]

10. Shanafelt, T.D.; Lee, Y.K.; Call, T.G.; Nowakowski, G.S.; Dingli, D.; Zent, C.S.; Kay, N.E. Clinical effects of oral green tea extracts in four patients with low grade B-cell malignancies. Leuk. Res. 2006, 30, 707-712. [CrossRef]

11. Dani, C.; Oliboni, L.S.; Vanderlinde, R.; Bonatto, D.; Salvador, M.; Henriques, J.A.P. Phenolic content and antioxidant activities of white and purple juices manufactured with organically- or conventionally-produced grapes. Food Chem. Toxicol. 2007, 45, 2574-2580. [CrossRef] [PubMed]

12. Santos, A.Q.; Nardin, P.; Funchal, C.; Almeida, L.M.V.; Jacques-Silva, M.C.; Wofchuk, S.T.; Gonçalves, C.A.; Gottfried, C. Resveratrol increases glutamate uptake and glutamine synthetase activity in C6 glioma cells. Arch. Biochem. Biophys. 2006, 453, 161-167. [CrossRef] [PubMed]

13. Dani, C.; Oliboni, L.S.; Agostini, F.; Funchal, C.; Serafini, L.; Henriques, J.A.; Salvador, M. Phenolic content of grapevine leaves (Vitis labrusca var. Bordo) and its neuroprotective effect against peroxide damage. Toxicol. In Vitro 2010, 24, 148-153. [CrossRef] [PubMed]

14. Cardozo, M.G.; Medeiros, N.; Lacerda, D.S.; De Almeida, D.C.; Henriques, J.A.; Dani, C.; Funchal, C. Effect of Chronic Treatment with Conventional and Organic Purple Grape Juices (Vitis labrusca) on Rats Fed with High-Fat Diet. Cell. Mol. Neurobiol. 2013, 8, 1123-1133. [CrossRef] [PubMed]

15. Ongaratti, B.R.; Machado, F.S.; Medeiros, N.S.; Destri, C.; Silva, E.R.D.; Quincozes-Santos, A.; Dani, C.; Funchal, C. Antioxidant and neuroprotective effect of organic and conventional white grape juices on oxidative stress induced by sodium azidein cerebral cortex of rats. Eur. J. Nutr. Food Saf. 2014, 4, 592-603. [CrossRef]

16. Wohlenberg, M.; Almeida, D.; Bokowski, L.; Medeiros, N.; Agostini, F.; Funchal, C.; Dani, C. Antioxidant activity of grapevine leaf extracts against oxidative stress induced by carbon tetrachloride in cerebral cortex, hippocampus and cerebellum of rats. Antioxidants 2014, 3, 200-211. [CrossRef] [PubMed]

17. Dani, C.; Pasquali, M.A.; Oliveira, M.R.; Umezu, F.M.; Salvador, M.; Henriques, J.A.; Moreira, J.C.F. Protective effects of purple grape juice on carbon tetrachloride-induced oxidative stress in brains of adult wistar rats. J. Med. Food 2008, 11, 55-61. [CrossRef] [PubMed]

18. Dani, C.; Oliboni, L.S.; Vanderlinde, R.; Pra, D.; Dias, J.F.; Yoneama, M.L.; Bonatto, D.; Salvador, M.; Henriques, J.A.P. Antioxidant activity and phenolic and mineral content of rose grape juice. J. Med. Food 2009, 12, 188-192. [CrossRef] [PubMed] 
19. Gabardo, T.; Peripolli, C.M.; De Andrade, R.B.; Gemelli, T.; Lima, J.D.O.; Oliveira, A.S.; Medeiros, N.S.; Wannmacher, C.; Dani, C.; Funchal, C. Assessment of changes in energy metabolism parameters provoked by carbon tetrachloride in Wistar rats and the protective effect of white grape juice. Toxicol. Rep. 2015, 2, 645-653. [CrossRef]

20. OIV-Organisation Internationale de la Vigneet du Vin. Recueil des methods internationals d'analyse des vinset des mouts, edition 2011. In Proceedings of the 8th Assemblé e Générale, Paris, France, 21 June 2010.

21. Georgiev, V.; Ananga, A.; Tsolova, V. Recent advances and uses of grape flavonoids as nutraceuticals. Nutrients 2014, 6, 391-415. [CrossRef]

22. Toaldo, I.M.; Cruz, F.A.; Alves, T.L.; De Gois, J.S.; Borges, D.L.G.; Cunha, E.P.; Da Silva, E.L.; Bordignon-Luiz, M.T. Bioactive potential of Vitis labrusca L. grape juices from the Southern Region of Brazil: Phenolic and elemental composition and effect on lipid peroxidation in healthy subjects. Food Chem. 2015, 173, 527-535. [CrossRef] [PubMed]

23. Zoecklein, B.W.; Douglas, L.S.; Jasinski, Y.W. Evaluation of the phenol-free glycosyl-glucose determination. Am. J. Enol. Vitic. 2000, 51, 420-423.

24. AOAC (Association Official Agriculture Chemistry). Official Methods of Analysis of AOAC International, 6th ed.; AOAC: Rockville, MD, USA, 1998.

25. Singleton, V.L.; Orthofer, R.; Lamuela-Raventós, R.M. Analysis of total phenols and other oxidation substrates and antioxidants by means of Folin-Ciocalteau reagent. Methods Enzymol. Oxid. Antioxid. 1999, 299 Pt A, 159-178.

26. Buege, J.A.; Aust, S.D. Microsomal lipid peroxidation. Methods Enzymol. 1978, 52, 302-310. [PubMed]

27. Reznick, A.Z.; Packer, L. Oxidative damage to proteins: Spectrophotometric method for carbonyl assay. Methods Enzymol. 1994, 233, 357-363. [PubMed]

28. Aksenov, M.Y.; Markesbery, W.R. Changes in thiol content and expression of glutathione redox system genes in the hippocampus and cerebellum in Alzheimer's disease. Neurosci. Lett. 2001, 302, 141-145. [CrossRef]

29. Bannister, J.V.; Calabrese, L. Assays for superoxide dismutase. Methods Biochem. Anal. 1987, 32, $279-312$.

30. Aebi, H. Catalase in vitro. Methods Enzymol. 1984, 105, 121-126.

31. Lowry, O.H.; Rosebrouh, N.J.; Lewis-Farr, A.L.; Randall, R.J. Protein measurement with the Folin phenol reagent. J. Biol. Chem. 1951, 193, 265-275.

32. Lin, C.J.; Lee, C.C.; Shih, Y.L.; Lin, T.Y.; Wang, S.H.; Lin, Y.F.; Shih, C.M. Resveratrol enhances the therapeutic effect of temozolomide against Malignant glioma in vitro and in vivo by inhibiting autophagy. Free Radic. Biol. Med. 2012, 52, 377-391. [CrossRef]

33. Yuan, Y.; Xue, X.; Guo, R.B.; Sun, X.L.; Hu, G. Resveratrol Enhances the Antitumor Effects of Temozolomide in Glioblastoma via ROS-dependent AMPK-TSC-mTOR Signaling Pathway. CNS Neurosci. Ther. 2012, 18, 536-546. [CrossRef] [PubMed]

34. Yin, H.; Zhou, Y.; Wen, C.; Zhou, C.; Zhang, W.; Hu, X.; Wang, L.; You, C.; Shao, J. Curcumin sensitizes glioblastoma to temozolomide by simultaneously generating ROS and disrupting AKT/mTOR signaling. Oncol. Rep. 2014, 32, 1610-1616. [CrossRef] [PubMed]

35. Pinheiro, F.V.; Pimentel, V.C.; De Bona, K.S.; Scola, G.; Salvador, M.; Funchal, C.; Moretto, M.B. Decrease of adenosine deaminase activity and increase of the lipid peroxidation after acute methotrexate treatment in young rats: Protective effects of grape seed extract. Cell Biochem. Funct. 2010, 28, 89-94. [CrossRef]

36. Raza, H.; John, A. Green tea polyphenol epigallocatechin-3-gallate differentially modulates oxidative stress in PC12 cell compartments. Toxicol. Appl. Pharmacol. 2005, 207, 212-220. [CrossRef] [PubMed]

37. Watjen, W.; Michels, G.; Steffan, B.; Niering, P.; Chovolou, Y.; Kampkötter, A.; Tran-Thi, Q.H.; Proksch, P.; Kahl, R. Low concentrations of flavonoids are protective in rat H4IIE cells whereas high concentrations cause DNA damage and apoptosis. J. Nutr. 2005, 135, 525-531. [CrossRef] [PubMed]

38. Rodrigues, A.D.; Scheffel, T.B.; Scola, G.; dos Santos, M.T.; Fank, B.; de Freitas, S.C.; Dani, C.; Vanderlinde, R.; Henriques, J.A.; Coitinho, A.S.; et al. Neuroprotective and anticonvulsant effects of organic and conventional purple grape juices on seizures in Wistar rats induced by pentylenetetrazole. Neurochem. Int. 2012, 60, 799-805. [CrossRef] [PubMed]

(C) 2018 by the authors. Licensee MDPI, Basel, Switzerland. This article is an open access article distributed under the terms and conditions of the Creative Commons Attribution (CC BY) license (http://creativecommons.org/licenses/by/4.0/). 